\title{
Entrenamiento Para El Uso Del Baño ${ }^{1}$
}

Millie Ferrar y Sara McCrea ${ }^{2}$

\section{¿Estan Listos?}

Esta usted pensando en entrenar su hijo para el baño? No precipite su decisión. Posiblemente usted siente presión de sus familiares y amigos en cuanto a esta decisión, o puede que también esta cansado de cambian pañales y piensa que su hijo necesita mas independencia. Sin embargo, antes de empezar el entrenamiento, asegúrese que su hijo este listo.

Entrenarlos para usar el baño es una meta de desarrollo, no un indicador de la inteligencia de su hijo o de sus habilidades como padre. Algunos niños están listos para empezar el proceso a la edad de 2 años, otros pueden no estar listos sino hasta la edad de 3 años.

Su hijo le dejara saber de maneras indirectas cuando el este listo para empezar el aprendizaje. Empezar este proceso antes de que el niño este listo solo causara frustración en ambos el niño como en usted. Tenga paciencia con el desarrollo de su hijo y así el entrenamiento para usar el baño se hará mas fácil.

\section{Señales De Que El Niño Esta Listo}

Para hacer éste proceso más fácil, asegúrese que su hijo muestre señales de estar listo para empezar. Entre más signos de que esta listo el niño muestre, el proceso será más fácil para los dos. Su hijo esta probablemente listo cuando:

- Se pueda ayudar a vestir y desvestir por si mismo.

- Pueda sentarse a jugar tranquilo por alrededor de 5 minutos.

- Tenga movimiento en los intestinos.

- Pueda mantenerse seco por dos horas.

- Le tenga nombre a la orina y a la defecación.

- Desee independencia.

Si el niño esta enfrentando otro tipo de estrés como un nuevo bebe en la casa o un cambio de guardería, empiece este proceso mas tarde. Espero por ahí de cuatro a 6 semanas después de tal eventualidad para empezar el proceso de entrenamiento.

1. Este documento FCS 2152-Span, uno de series del Departamento de Familia y Juventud y Ciencias de Comunidad, Servicio Coperativo de Extension de Florida, Instituto de Alimentos y Ciencias Agricultura, Universidad de Florida. Publicacion original en Diciembre 10, 2000. Revizado por Heidi Radunovich, Departemento de Familia y Juventud y Ciencias de Comunidad, Enero 2007. Traducido Junio 2007 al español por Rafael Arango y Samara Vasquez. Visite la pagina de EDIS a http://edis.ifas.ufl.edu.

2. Millie Ferrer, Desarollo Humano, y Sara Mccrea, assistente graduado, Departamento de Familia, Juventud y Ciencias de Comunidad, Servicio Coperativo de Extension, Instituto de Alimentos y Ciencias de Agricultura, Universidad de Florida, Gainsville 32611.

El Instituto deAlimentos y Ciencias Agricultura (IFAS) es una igual oportunidad de empleo: Accion afirmativa authorizada para proveer investigacion de educacional y otros servicios solo para individuos y otras instituciones que funcionan sin obsevar, raza,color, religion, edad, desabilidad, orientacion sexual, estado matrimonial, origin nacional, opinions politicas o afiliaciones. Para mas informacion en como obtener otras publicaciones de Coperativo de Servicios de Extension de Florida/ Instituto de Alimentos y Ciencias Agricultura/ Universidad de Florida/ Larry Arrington, Dean. 


\section{Como Empezar: Pre-} Entrenamiento Para Usar El Baño

Una vez el niño muestre señales de estar listo, el debe estar por al menos una semana en la etapa de pre-entrenamiento. Durante este tiempo, lo padres deben de:

- Decirle al niño que ha mojado su pañal y darle un nombre a cada necesidad.

- Decirle lo incomodo que es tener el pañal mojado para que así el cree esta sensación.

- Permitirle ver como otros miembros de la familia usan el baño para ayudarle a entender los pasos envueltos. Esto le da la oportunidad para que haga preguntas.

- Cambiarle los pañales sucios inmediatamente. Esto ayudara que el niño note lo desagradable que es tener los pañales sucios.

Algunos niños necesitan más de una semana para completar el proceso de preentrenamiento. Es común que se tomen hasta un mes. No se preocupe por la velocidad. Que tan cómodo se sienta el niño es más importante que que tan rápido el niño aprenda.

\section{Verdadero Entrenamiento}

Una vez el niño este listo para el entrenamiento, tenga escritas las actividades de uso del baño que presente el niño. Después de unos días usted ya sabrá las horas en que el niño usa el baño.

Para enseñar el niño a usar el orinal, ponga el orinal en el baño y espere que el niño pregunte que es eso. Permitir que el niño descubra el orinal por si solo, ayuda que el niño sienta control sobre la situación. Una vez le haya explicado al niño para qué es el orinal, siéntelo varias veces al día, especialmente a las horas ya antes escritas. Si en uno de los intentos el niño usa el orinal, prémielo por sus esfuerzos.

Permita al niño estar sin pañales por un lapso del día cada día. Esto le ayuda a entender que el pañal será eliminado. Explíquele que cuando necesite usar el baño, el debe usar el orinal. Al principio, trate que el niño orine cada hora. El se resistirá especialmente si esta jugando. No le haga la pregunta, Ej., “¿Necesita usar el orinal?” Lo más probable es que diga "No!”

Simplemente dígale "ya es hora de usar el orinal.” Dígale que solo lo intente. Asegúrele que el va a volver a jugar después de usar el baño. Así no orine, prémielo por tratar.

\section{Que Esperar}

Durante esta etapa, su hijo tendrá accidentes, así que prepárese para la frustración que podrá experimentar. Mantenga la calma y continúe dándole apoyo a su hijo. Cuando ocurra un accidente, dígale "Esta bien, accidentes ocurren. Para la próxima me avisas.” Déjelo que intervenga en la limpieza de su propio accidente.

Evite desmotivarlo. Críticas pueden afectar su autoestima. No lo regañe. Regañarlo por un accidente solo hará la situación peor. Reconozca que su hijo controla el manejo de vaciamiento de su riñón e intestino, no luche por algo que no puede ganar.

Genuinamente premie el niño cuando lo logre. Dígale que se siente orgulloso de el y que el debería sentirse orgulloso de si mismo. A medida que va usando el baño mas a menudo, permítale hacer mas cosas como bajarse o subirse los pantalones, limpiarse, descargar el inodoro y lavarse las manos.

Otras técnicas que puede intentar cuando este entrenando a su hijo para usar el baño: 
- Permítale tener un juguete en el orinal. Un juguete que en realidad disfrute, que solo use cuando este usando el baño.

- Llévelo a la tienda a comprar interiores para niños grandes. El preferirá interiores con animales o héroes favoritos.

Dichos actos mantendrán a su hijo interesado y harán de esta, una alegre experiencia.

\section{Desafios}

Si experimenta problemas durante el proceso de entrenamiento, analice que podría estar causando sus dificultades. Pregúntese lo siguiente:

- ¿Estaba mi niño listo cuando lo empecé a entrenar?

- ¿Esta mi hijo experimentando otros estreses (un nuevo bebe, nuevo colegio, nuevo hogar, etc.)?

- ¿Tuvimos suficiente tiempo en el preentrenamiento?

Cuando ya haya encontrado el problema, vuelva a la etapa donde el niño tuvo éxito. Quédese en esa etapa hasta que el niño demuestre que ya esta listo para la próxima etapa. Así, poco a poco avanza a la próxima etapa.

Evite que usted o el niño se frustren. Tenga en mente que el entrenamiento para el baño no es una carrera! Vea este proceso como cualquier otro objetivo que lograr (como el crecimiento de los dientes y el dormir toda la noche). Darle mas importancia a este proceso solo causará mas dificultad para su hijo. Sea tolerante, los días secos llegaran antes de lo pensado!

\section{Referencias:}

DeBord, K. 1997. Toilet Learning. National Network for Child Care, N. Carolina Coop. Exten. Serv. Raleigh, 4pp.

Hussey-Gardner, B. 1999. Toilet Training. Provided by the VORT Corp. Condensed from the book, Toilet Training.

FamilyDoctor.org. 2006. Toilet Training Your Child.

http://familydoctor.org/online/famdocen/hom e/children/parents/toilet/179.html

Keep Kids Healthy. 2003. Starting Potty Training. http://www.keepkidshealthy.com/parenting_t ips/potty_training/start_potty_training.html

Pike, L.B. 1998. Toilet Training. Univ. Missouri Exten. Columbia, MO. Pub. \#GH6128.

Prezioso, P. 1996. Learning to Love the Potty. Avant Gardens: The Standard Times.

Shimm, P.H. \& K. Ballen. 1995. Parenting Your Toddler. Addison-Wesley Publishing Co. NY, NY 227pp.

Stephens, K. 1999. Toilet Training: Children Step Up to Independence. Child Care Information Exchange. Issue \#125. Pp. 7680.

*Esta publicación se refiere “al niño” para referirse a niños y niñas. 